\title{
Review on Various Application Bio Fuels
}

*C. Venkateswaran, Vishal Fegade, M. Ramachandran, Vimala Saravanan, Vennila Tamilarasan

Management Studies department, Maharishi Markandeshwar (Deemed to be University), Ambala, Haryana. India.

NMIMS University, Maharashtra, India

REST Labs, Kaveripattinam, Krishnagiri, Tamil Nadu, India.

*Corresponding author Email: venky.professor@gmail.com

\begin{abstract}
Biofuels are renewables derived from microorganisms, plants or animals Are energy sources. Examples of biofuels are ethanol (mostly in the United States) Cane is also produced in Brazil), biodiesel (from vegetable oils and liquid animal fats) Derived), green diesel (derived from algae and other plant sources) and biogas (Derived from animals) (fertilizers and other digestive products). Biofuels can be solid, liquid or May be gaseous. They are most effective in the last two forms because it is transport, Facilitates distribution and clean combustion. Biofuels from organisms Are defined as derived fuels, otherwise known as organic substances. This includes any plant or moss material (including wood) and animal waste. This kind of Fuels are considered renewable energy sources because they are sustainable for life Are naturally filled by rotation. Fossils such as coal, oil and natural gas It is an attractive alternative to fuels. These products have been around for thousands of years Developed and costly and environmentally harmful processes Should be extracted from deep ground using. They are much faster than they are produced Are consumed in proportion, i.e. sooner or later the entire distribution of the planet's fossil fuels Will be reduced especially if they are reduced to the current rate. Simply put, life Fuels are one of all fuel sources made from organic materials Say c-by. However, not all biofuels are created equal. In fact, There is a clear difference between primary biofuels and secondary biofuels, they are differentiated based on how they are produced, but they are It also affects how they are commonly used. Biofuels are from an organism Obtained fuels - i.e. plant or algae material or animal waste. Petroleum, Coal Unlike fossil fuels such as and natural gas, biofuels are renewable energy sources. Are considered as evidence because they can be filled immediately.
\end{abstract}

Keywords: Bio-Fuels, Microalgae, Ethanol, Agricultural Bio-Fuels, Vegetable oil Bio-Fuels

\section{Introduction}

Biofuels derived from biofuels, plant or algae or animal wastes. Such fodder can be filled immediately Because, unlike fossil fuels such as petroleum, coal and natural gas, biofuels are a source of renewable energy. Considered. Many consider the material to be used only for transportation. But biofuels can provide hydrogen, not oil Cleanses, works with cooking oil and many more. Biofuels Energy requirements from automotive fuels to central home heating Can act as an alternative to change. Heat can be generated by using some long-exploited biofuels such as wood directly as a raw material. Heat, in turn, can be used to run generators in power plants. Many existing electrical facilities are made of grass, wood or other types Burn organisms. Global demand for energy is expected to continue to grow significantly, and alternative, sustainable solutions to meet those needs It is widely accepted that solutions need to be found. For many in the energy industry, biofuels are its cleanest and most renewable Are considered to be the most important for future energy production due to the properties. Microalgae are single-celled photosynthetic microorganisms that are exposed to sunlight and water And live in salt or freshwater environments that convert carbon dioxide into algae. The project is to harvest from large-scale moss farms Developed technology to produce biodiesel and other valuable by-products from manufactured microalk biomass. Microalkas Carbon Organisms such as microscopic plants that convert dioxide and sunlight directly into biochemical energy. Microbiology or microphysiology are microscopic algae that are invisible to the naked eye. They live in both phytoplankton, water column and sediment, commonly found in freshwater and marine systems. They are unicellular species that can be individually or in chains or groups. Bioethanol is an alcohol produced by microbial fermentation, which is often produced from carbohydrates or starch-tolerant plants such as corn, sugar cane, sweet corn or lingo cellulosic biomass. The fermentation process involves less energy consumption and the production method is much simpler than biodiesel. Ethanol is a flammable, colorless liquid. When used as an alternative fuel, ethanol is simply referred to as bio ethanol. Bio ethanol is often used as a motor fuel or as an additive in gasoline and is an option for more and more "renewable" energy. Bioethanol is a liquid biofuel that is produced by ABE fermentation of various types of fodder such as corn, soybeans, wheat straw, wood chips and most recently microalgae. Bioethanol is a renewable biofuel that is oxidized (35\% oxygen), thus providing the ability to reduce automobile emissions.

\section{Bio-Fuels}

Globally, estimates of biofuels are very high. Despite the high price of oil in the world today, tradition The price of biofuels is not compromised with dependent fuels. Biofuel Economy 21st Has been growing rapidly for over a century. The growth of the hydrocarbon economy in the last century Designed, the same forces now in the biofuel economy and its biofuel plants Design. Because biofuels have their own merits for the environment, The effective contribution of biofuels to the 
transportation sector will lead to rapid growth in the future. Biofuels are industrialized for many reasons And are considered appropriate technology by developing countries. [1] If the public support (transportation) system uses biofuels, only the national indicator targets Can be achieved. There are some supports to encourage the supply of fodder reserves for biofuel production, The main approaches are biofuel tax and tax reduction. Production of biofuels three Divided into categories: first, second and third generation. Second generation biofuels Production processes depend on cellulose hydrolysis and sugar fermentation. [2] By the gasification process Biomaterials are very useful for the production of synergies (synthesis gas). This sync Can be converted into liquid biofuel with the help of many catalytic processes. Biomass from algae The current production process of fuels is classified as a third generation process. Algae Can produce oil, which can easily refine some contents of diesel and petrol. Land, For various sustainability efforts and biofuels to protect communities and biodiversity Various projects are being implemented. These initiatives include voluntary organizations, government agencies and Includes private companies. Of biofuels There is an urgent need to combine public and private investment to implement commercialization. [3] The effectiveness of the extraction always depends on the solubility of the vegetable oil in the extract. Compressor Different types of oil presses are used to extract. However, three extracts The oil yield of the methods was always low. Crushed seeds are usually mechanical Are used to extract. Vegetable oils as biofuels for biofuel production Chemical extraction is the most suitable method if considered. Despite the challenges, algae are alive High content of nitrogen biomass derived from and promotes the development of catalysts for HPR Limited information has given more hope to this resource of future biofuels [4].

The economic parameters attractive, biofuels can be manufactured at a separate biofuel plant. In this regard, the source and location of the organism, the type of organism, the cost of transport, the biofuel Production method, hydrogen availability, survival and associated capital costs Important facts. , And overall emissions. Origin of Biofuels in HPR Downline Options Can have a significant impact. For example, biofuels from vegetable oils and more Can be taken to a petroleum refinery for processing and / or joint processing. Is Nestl Iya the sole owner of the biofuel production developed by the Oil Corporation? [5] In recent years, the use of liquid biofuels in the transportation industry has become rapidly global Has shown growth, often focusing on energy savings and reducing GHG emissions Policies cause. First generation biofuels that have now reached the economic stages of production Mainly food and oil crops such as rapeseed oil, sugarcane, sugarcane and maize and plant Using conventional technology from oils and animal fats Are extracted. [6] Production and consumption of liquid biofuels are projected to continue to grow. In general, the use of first-generation biofuels in global food markets and food security, Great controversy, especially due to their impact on the most vulnerable areas of the world economy Has caused. Like other plant-based biofuels, microalgae are solar powered Provides a way to collect, modify and store in chemical form. Biofuels For extraction, the net energy output of the fuel To maximize, it is important to strike a balance between drying efficiency and cost-effectiveness. [7] We have five external factors that induce or inhibit latent growth in both of our cases We have identified: oil supply, local air and water quality, EU agricultural policy, Climate change and technical aspects. These factors are of international and national origin, But common to both countries and generally by specific biofuel detection systems (PIS) is not affected. As is clear from our analysis, the study of their influence on BIS dynamics Differs between the two systems made. [8] The first factor is the insecurity of the oil supply, Mainly represented by oil price shocks. Oil-based crises Have had an impact on oil dependence in the industrial world. Alternative energy sources are being sought Are coming, and more biofuel technologies are being developed to use them. Since then, however, oil prices have fallen and stopped being the driver of change. Cheap fossil fuels have become an economic barrier to all renewable growth. Oil This changed only at the end of the study period as prices began to rise. The second factor is local wind And concerns about water quality. The issue arose on the political agenda from all over Europe. In the transportation industry it is as new as catalytic converters and pure diesel engines Led to discoveries. It also became an argument for activating biofuels [9].

The Energy consumption for dehydration via the wet path as the heat drying process is abandoned The dry path Via only $12 \%$. The process of extracting oil through the wet path oil through the dry path It uses 2.8 times more energy than the extraction process. Downstream from cultivation Considering the overall effects of the whole chain up to change, the total energy input is either way Comparable. Also, the FER of the dry path is slightly higher than the wet path. Drying Is slightly higher than the path. [10] The perfect and efficient combination of drying techniques By selecting, the basic case of the dry path reaches FER 2.38, as some critics think, To produce biofuels from microorganisms via the dry route. However, dry One realizes that the high FER pyrolysis process of the path benefits from high thermal efficiency (95\%) To. Although pyrolysis oil has an energy output of about $50 \%$, it is currently in production Pyrolysis oil specific Used for a number of applications only. [11] What I call "pushing towards biofuels" is primarily a North American phenomenon, and bio Despite the potential for fuel, growth is a global goal. Biofuels are real Brazil has had great success in transforming into energy (the sustainability of their approach is debatable Though). Elsewhere it "pushes towards biofuels", but not this article For purposes, it focuses on American culture and politics. Two anonymous reviews of this Conditional, however, is the most accurate original manuscript. Most of these objections No initial effort was made to explore the technical and political debates to qualify for this initial study Only necessary. Very concise and against technically explicit definitions There is the Impressionist story. Against the standard scientific practice of providing conditional definitions Creating a rational and ethical argument, as an alternative way of making subsequent arguments It also aims to modify the interpretation of the formal ecosystem. That of democracy When it comes down to it, conditional technology is a definition Provides, the argument proving discussions about self-failure or biofuels is prudent. [12] SCL PHB and MCL PHA as hydroxycalconate methanol methyl esters 
(3HBME and 3HAME) The role of PHA-based products as biofuels by converting was first mentioned Generated combustion heat comparable to ethanol.

When used as a fuel additive, petrol And 3HBME and 3HAME can be used at a rate of 10-30\% in chemical fuels such as diesel. Based on oxygen content, dynamic viscosity, flash point and boiling point, 3HBME Has similar or better properties to fuel than ethanol. Also, glucose and other Production of another biofuel by the PHB synthesis pathway embedded from the metabolites It has been reported that most of the use of PHA as a source of biofuels Seems important guarantee because it does not require much refined PHA. Therefore, PHA can be obtained from activated sludge or nutrient-rich wastewater, for food Does not compete with humans or animals, resulting in lower costs. [13] Above for path selection and yield barriers for by-products in microbial systems We believe that the approach has implications for many aspects of industrial biotechnology Hope: First, the pre-process metabolism in the context of energy balance It enables selecting; Second, it improves substrate selection to increase yield; Third, it is not just for biofuels, but for any biotechnology product Also applies to engineering; Finally, the systematic development of the second generation biofuel industry This underscores the importance. Based on the selection of precursor metabolites, the substrate And it also significantly affects the final energy balance of the entire path with respect to substrate production Is clear. A technique commonly used to integrate more chain-elongated molecules Is the continuous contraction and reduction of acetyl COA molecules. More about this source text Source text required for translation information Send feedback Page panels [14] Nevertheless, the impact of crude oil futures on the future of corn and soybean price leaks It is not clear why crude oil prices have not been active in recent times. In fact, bio Most of the costs associated with producing fuels are generally fossil Will be more than fuels. In the era of low crude prices, Humphreys and McClain and Waterbuck basically adopts a portfolio approach, renewable Energy prices are unrelated to each other or have little to do with crude oil prices Argue that. [15] As expected, the effects of the price leak, corn and soybean futures prices Both confirm our hypothesis that future crude oil prices will be positively affected. Although prices of corn and soybeans have risen more than the cost of production, biodiesel and Biodiesel production has been profitable in recent years, Mainly due to high crude oil prices and increased subsidies and average yields per hectare.

\section{Microalgae}

Three popular ways to grow microalgae for fuel Open pool systems, closed pools Systems and engraved photovoltaics or PBR. Closed pools Open pools Will be similar, but they will be covered for colder climates. Standard 15C for open pool system Requires low temperature, low maintenance, low cost to set, but low yield. However, bio The cost of microbes for fuel production will fall and the world's transportation fuel supply Significant obstacles have not yet been overcome before the impact. [10] Microalgae as a potential source of various food and biological products used in the pharmaceutical industry Is. Practical sources of omega-3 in microalgae are usually ecosapentaenoic acid (EPA). And decosahexaenoic acid (DHA). Compared with fish, microalgae are self-sufficient in omega-3s Produces and makes the process straight and economical. Chlorophyll is from microorganisms Another pharmacologically important product obtained. [16] High quality animal from aquaculture to farm animals Microalgae have been reported to play an important role in nutrition. Comprehensive Nutrition and Toxicology Assessments As a valuable fodder supplement for algae organisms or as an alternative to conventional animal feed sources Have proven to be applicable. Another for lipid extraction from microalgae The method is solvent extraction. Fermentation of recent attempts to produce ethanol Focus on microorganisms as feed for the process. Microbes are good for biogas production Despite providing energy, commercial production has not yet been implemented. In the microalga conversion business As more companies come forward we can hope that a more detailed picture will come out. Microalga feed stocks With land use change and food crops Since they are not competitive, the scope for implementing them is better. [17] Microbial biodiesel production requires high levels of algae biomass. Most algae species Mandatory prototypes, therefore, need light for their development. Many used to produce microorganisms Cultivation techniques have been developed by researchers and commercial manufacturers. Phototrophic microalgaes are commonly found in open-air pools and light catalysts Are grown. Open pool cultures are economically viable, but land use Raise issues such as cost, water availability and suitable climate. Also, fungi, bacteria and There is also the problem of being contaminated by protozoa and competing with other microorganisms. These factors Can be simplified and reduced to three main groups; Cultivation of microorganisms, harvesting and processing of organisms. [18]

Micro alkaline biodiesel has been proposed as the most explicit choice. Microalks Oxygen-producing chlorophyll "A" based microorganisms, mostly autotrophic, Atmospheric CO2 is used as the primary carbon, with some being an organic source of carbon in addition to $\mathrm{CO} 2 \mathrm{Can}$ be used or even grown together as a heterotrophic ally. Carbon by carbon. Only the seeds of the vascular plant are used in the production of biodiesel derived from the plant, and The remaining organisms are generally considered waste. [19] As a result, from microorganisms The aerial production yield of lipids is many times higher than the technology of already grown oilseed crops Is abundant and does not require fertile lands. Microalgae as a system for biodiesel production Another important factor in choosing is their minimum nutritional requirements. Microorganisms With fresh or seawater, marginal lands and wastewater treatment plants or industrial parks Can be grown together. Because most microalgaes are so small, their small size and Extra-cellular materials quickly clog the tested filters. [20] The presence of this enzyme in the microalga allows fermentation behavior when oxygen is low (Important in the metabolism of hydrogen production by microalgae). Glucose-6-phosphatase and Metabolic pathways containing the enzymes ATP transesterification differ in algae cells There is evidence that they work. Nutritional stress, especially for nitrogen and foods Silicate has been shown to greatly increase oil production in microalgae, but in total biology At the expense of production. This strategy 
greatly reduces the consumption of sugar substrates, thereby Opens the door to low cost biodiesel production from microorganisms. Moss harvest is diluted The process of concentrating the moss suspension into a thick moss paste. Is usually the microbial harvest It is a single or two step process that involves harvesting and dewatering. Biodiesel Microalloys have the ability to produce lipids that can be used to produce. Existing Chemical esterification processes require a fatty substance without water. Therefore Microbial drying is considered in some processes. The simple sedimentary structure is naturally high Suitable for microorganisms with sedimentation rates. Whether it is thickeners or clarifiers, standard Is done in water treatment plants with processes. [21] Microbes are easy to grow because only simple nutrients need to be provided. Most research on microbiology is based on clean but expensive photovoltaics or open Focuses on growing algae in ponds, which are cheap to maintain but not polluting Likely. Biofuels made from microorganisms face other biofuels today Although capable of solving many sustainability challenges, their biofuels Producing using available technology is not economical, and the existing algae The species cannot be grown cheaply. At the same time, biodiesel as a source of fatty acids Produce usable oil. Microalgae harvesting is two-stage Is the process, which is total harvesting (separation of biomass from total suspension) and thickening (Aggregation) includes. Due to the small size of the algae and the low density, this The move is a major hurdle in current biofuel technology, which is the cost of capital Increases. Microalgaes have the potential to use large amounts of $\mathrm{CO} 2$ because, Have the ability to adjust. Atmospheric, industrial exhaust gases and soluble carbonate salts Microalgae can efficiently adjust CO2 from a variety of sources, including [22] Microalgae can efficiently adjust CO2 from a variety of sources, including Microbes do not need fresh water to grow and cultivate, and they are not edible, therefore It has no effect on the food chain of humans and animals. Seasonal conditions, Atmospheric CO2 reduction and wastewater treatment. [23].

Lignocellulose products in the microalga cell wall The absence simplifies the pre-treatment process and reduces the overall production cost. The food and processing power of microalgae industrial wastes is the energy produced by algae Is less than. These pigments are used for tumorigenesis, neurological disorders and optical diseases. Are important in treatment. Microalgae are also rich sources of protein. Of essential amino acids Production increases the ability to use them as proteinrich foods. Bio ethanol Algae sugars are the best ingredients for production. As mentioned above, some types of microorganisms are high in sugar Are too adventurous to produce bio ethanol due to the content. However, in algae biomass The carbohydrates in are mostly in polymeric form and produce biothenol Must be transferred to the monomer unit for immediate fermentation by microorganisms. Biologically active Due to their immense potential for producing natural products within, microalga Natural with strong antioxidant effects Is one of the richest and most economical sources of compounds. [24] Separating lipids from microorganisms is another biotechnological challenge because of the solid cell wall The oil is hard to get out of. The oil is usually squeezed out of the dried algae Is extracted, and the mash is refined with a solvent to obtain the remaining oil. The development of cyanobacteria and microalgae for mass energy production is in its infancy. Its Due to the sophisticated technologies used for the small-scale production of high-value products Basically based on cost estimates. [25] Growing and processing algae Utilizes energy in infrastructure and operation. Cultivation and harvesting process and Depending on the yield, the potential inputs of the microbial production will be higher than the energy output. Genetic engineering to increase energy production in microalgae and cyanobacteria Although applications are at an early stage to handle the central carbon metabolism in these organisms Significant advances in the development of genetic tools by micro-algae modeling systems used Have recently been reached. These improvements can be extended to many occupational species. Biofuels Genetic engineering to promote cyanobacteria / microalgae as biofuels for production This section focuses on possible ways. [26] Stable from relatively inexpensive mineral molecules to highly valued isotopic organic chemicals As a source of isotopically labeled compounds due to their ability to bind isotopes Microalgae are very suitable. The microbe has been exploited by humans for thousands of years. BEAM Network, a microalga bio, supported by the University of Murdoch in Australia The technology is believed to have grown and diversified significantly over the past 30 years. However, there are some improvements and pigments, fatty acids and healthy foods There are commercial microbial applications included, only a few hundred of the thousands of microbes Are studied and cultivated on an industrial scale. Business of Microalka The possibilities for applications seem enormous, but have grown over the last 50 years The number of commercially available products is still small. [27]

Micro algae production in open ponds Is. Although numerous biochemical products are available from microorganisms, the main commercial material There seems to be a "healthy diet" that can generate health benefits, but it is fashion and May also be subject to rage. The second major source of microalgae commercial use today The component appears as food additives in the form of carotenes, pigments and fatty acids. Artificial These have functional advantages over products or products from other natural sources May contain, but they may also be less expensive. More about this source Send the required source text feedback for translation information Page Panels [28] In nature, the microscopic algae accumulation of lipids increases under certain conditions, so more biodiesel To naturally accumulate fats in algae when selecting and promoting algae for production The factors that lead to it need to be kept in mind. Microbes thrive in nutrient-rich (eutrophic) water Known to grow, which often leads to algae blooms. With high potential for biodiesel Microalgae for oil production and fodder production for other biofuels Very relevant. Produces oil that is more capable of biodiesel, as well as other organisms Microalgae are also well suited for forage production for fuels. [29] High efficiency algae biodiesel Development of production technologies, bio-hydrogen, biogas, bioethanol and fast growing Applies to biomass-to-liquid (BTL) approaches using algae. BTL, bio-hydrogen And below because biomethane processes are particularly related to the micro algae system Is discussed. Bio ethanol is not described here because of its presence with microorganisms The processes used for production are similar to 1st generation technologies, including Fodder reserves have been established, 
with fodder derivatives derived from corn and sugarcane Using. As the efficiency of bio-production per hectare is 5-30 times higher than that of crop plants As estimated, microorganisms are a major center of interest.

\section{Ethanol}

Biofuels Renewable fuels and biodiesel derived from biofuels (Equivalent to petrol) or biodiesel (diesel-equivalent) and biogas (e.g. methane) or Includes gaseous forms such as hydrogen. In this review, our on Liquid Biofuels We focus on the discussion. Enzyme hydrolysis for long-term low-cost bio-ethanol production Many experts believe that is important. [30] The second controlling factor in biochemical metabolic pathways is from the breakdown of hemi cellulose In conventional industrial applications to digest the produced five-carbon sugars (e.g. silos) (E.g., beer fermentation) is the inability of the yeasts used. Hydrogen, Methanol or Dimethyl Ether (DME) Synchronizers can be converted to different fuels including. From Cinchona by the Fisher-Drops (FT) package Synthetic diesel and petrol can also be produced. Of biofuels food prices Although charged for proportion, it deserves some offense. In the last three years, it is Undoubtedly food prices Contributed to tightening and rising food prices. [31] Biofuels are widely classified as primary and secondary biofuels. Primary biofuels are used in unprocessed form, primarily for heating and cooking Or as fuel for the production of electricity, such as wood chips and particles. Secondary bio Fuels are produced by biological processing e.g. Ethanol, biodiesel, DME Etc. can be used in vehicles and various industrial processes. Fuel wood, charcoal Primary biofuels are used in unprocessed form, primarily for heating and cooking Fluid like oils; Or gas such as biogas (methane). Bioethanol is usually from yeast Fluid like oils; Or gas such as biogas (methane). Bioethanol is usually from yeast Fluid like oils; Or gas such as biogas (methane). Bioethanol is usually from yeast Organic based with higher sugar fermentation content than manufactured enzymes Made from materials. Yeast contains six carbon sugars (mainly glucose) ethanol Converts because starch is much easier to convert into glucose than cellulose. Fermentation Processes to initially convert glucose into ethanol after separating the sugar from the raw material Use yeast. If ethanol is produced using renewable biology, that is Called bioethanol. Global production of firstgeneration bioethanol in 2006 was approx 51 billion liters or 35\% of the total. [32] China and India account for $11 \%$ of world ethanol production in $2006 \mathrm{Had}$ a share, and production in other countries was very low. Many countries are now first generation Involved in the expansion of ethanol production, the largest expansion in the United States and Brazil Show plans. Ethanol can be mixed with gasoline or modified in its pure form May burn in spark-ignition engines.

In comparison, a liter of ethanol is a liter of gasoline Contains $66 \%$ of the energy provided, but has a high octane content, and with gasoline for transportation When mixed it enhances the latter performance. Ethanol burns fuel in vehicles Improves emissions of carbon monoxide, unburned hydrocarbons and carcinogens Reduces. Ethanol has only a trace amount of sulfur compared to gasoline. Therefore, Mixing ethanol with gasoline helps to reduce the sulfur content of the fuel and thereby acidify it Reduces emissions of sulfur oxides and carcinogens, important components of rain. Ethanol The use of biofilms containing directly fermentable sugars in ethanol production Is a less complex method used. [33] Sugar, the main commercial commodity, is extracted from sugarcane. Other parts of the plant called "pagos" still use the sun's chemical energy Have. Like any organic material, pegasus generates heat when it burns. Another organism The fuel is ethanol, an alcohol distilled from corn. Wood and other lignocellulose The potential for ethanol production from is greater than that for corn. Cane, sweet potatoes, Maize and sweet corn are currently used for carbohydrate production and animal feed Commercially cultivated as agricultural crops. Ethanol from the wet grinding process Is being prepared. Many large ethanol manufacturers use this process, which is high in fructose Also offers products such as corn dessert. Ethanol generally increase octane rating It is also used to improve the emission quality of petrol. Fats and oils Fatty acid that reacts chemically with methanol or ethanol (the usual choice of methanol) Form a chemical compound called methyl esters. Various esterification of bio-diesel Can be prepared using technologies. Most of the bio-diesel currently produced is soybean Uses oil, methanol and alkali catalysts. Soybeans as a food item The high value of oil makes low cost fuel production very challenging. [34] Ethanol from carbohydrates by fermentation is a historical industry in beverage production Is an early application. Its production is due to the recent use of ethanol as a fuel Increased. Most ethanol is currently made from sugarcane or corn. Bio Ethanol can be used directly in cars designed to run on pure ethanol or with gasoline Mix and make "Kashohole". Anhydrous ethanol is required to mix with gasoline. Usually use a mixer No engine modification required. Ethanol is an octane-increasing, pollution-reducing additive in lead-free gasoline Can be used. More renewable than a mixture of ethanol and ethanol from natural gas Alcohols are currently expensive. [35].

Bio-methanol (in sugar extract) parallel to bio-ethanol production From) Simultaneous production seems economically attractive. Ethanol from sugarcane Produced mainly in developing countries with warmer climates and generally in IEA countries Cheaper than ethanol available from grains or sugar beets. Enzyme Starch or sugar for ethanol derived from a cellulosic raw material using hydrolysis Requires more processing than basic fodder, but fodder for grass and trees The cost is generally lower than for grain and sugar crops. Target reductions in alternative costs If possible, cellulose ethanol in OECD countries The total cost of production is less than that of grain ethanol. [36] Ethanol is made from pyruvate in two steps: pyruvate decarboxylase pyruvate Converts to acetaldehyde, and alcohol lowers dehydrogenase to acetaldehyde to ethanol. Today's major biofuels are ethanol, such as sucrose and starch currently derived from sugarcane Produced using fodder reserves. In Brazil, cane juice and cane molasses Are used as sources of sucrose. Industrial ethanol yield stoichiometric in sucrose The maximum may be up to 93\%, because Saccharomyces cerevisiae and closely related Yeast strains are used as hosts. Ethanol for fermentation of cellulose and sugar Two major metabolic engineering approaches to delivery have long been studied. The maximum attainable ethanol concentration depends on the host and the medium 
mixture, but in general 4 to $16 \mathrm{wt} \%$ depending on the host. For distilling ethanol from dilute fermentation broth Processes were also known in ancient Egypt, but considerable for distilling ethanol from fermented broth Requires power input. Distillation is the production of corn ethanol rather than cellulose ethanol Indicates a higher percentage of the cost because of pre-feed treatment and cellulose production Cellulosic ethanol still dominates the planned cost. [37] Bioethanol is a liquid alcohol produced in two steps. In the first stage, the yeast Fermentation of carbohydrates using hydrogen ethanol (water and maximum 95.6\% ethanol) Produces. In the second stage, solid absorption, extraction distillation or membrane to obtain anhydrous ethanol The remaining water is removed using a separator. In spark-ignition engines Bioethanol three based on the raw materials used and mixed with gasoline Classified into generations. Ventilation in thermochemical production systems, available Pyrolysis, liquefaction, supercritical fluid extraction and aqueous phase modification Include. In addition, bio-methane vapor reform can lead to bio-methanol synthesis. Wheat ethanol Mainly used in Germany, France and the United Kingdom. Especially sugar beets Used in France, Germany, United Kingdom, Czechoslovakia and Belgium. It is interesting to note that the impact of biothanol decreases as the percentage in the mixture increases. Another interesting indication is the use of biofuels for emissions (negative impact). While guaranteed, the raw materials will always be second generation: fertilizer, Poplar, Miss Kane, remnants of the forest, wheat straw, Lingo cellulose waste and bio-waste, Carinata \& Lay. Crops. [38] Ethanol, in contrast to biodiesel, is a composite biofuel, the final composition of which depends on the type of feed. Does not vary. Ingredients are sugar and starch crops, which are basically pre-treated, fermented and Processed by yeast and other microorganisms. The main sugar crops are sugarcane and Sugar beet. Sweet rice turns into an interesting ethanol ingredient in many uses, its The seeds are edible and contain sugar in its stems. The main starch crops used today Corn and wheat; Also low in potatoes, cassava and corn grains. Sugar crops generally produce more ethanol per hectare than starch crops. Further (2) Sugar can be fermented directly, while starch elongated polymers for protocol fermentation The yeast must be hydrolyzed before being added. "Wet grinding" and "dry grinding" Are two to treat when starchy crop parts enter the process chain The most common methods are. When wet grinding, the grains are soaked and starchy (grain Endosperms) and other high-protein and high-fiber components Products (corn oil and syrup, gluten, germ) Form. Food, vitamins and amino acids).

\section{Agricultural Bio-Fuels}

If people believe that liquid transport fuels derived from plant-based fodder stocks will expel food from the mouths of hungry people, there is an ethically powerful argument against the whole set of technologies dedicated to improving the biological potential of plant products into combustible fuels. , As well as research on agriculture and energy policies aimed at increasing the use of biofuels. [39] This article or section needs sources or references that appear in credible, third-party publications. Ethics of biofuel development. Although philosophers' analyzes ultimately have an impact on human behavior, they operate at some point from decent declarations aimed at telling What others should do. It is in this latter sense that this article deals with the cultivation of biofuels Is an exercise in ethics. First, between food and fuel consumption for agricultural crops Tensions are actually a specialty within a very comprehensive and systematic disregard for the interests of the poor It should be noted that the phenomenon. The answers to the fuel debate against food could not solve the basic ethical question of resource allocation because it Transforms biology from non-food agricultural sources. [40] However, global food prices Any one of these situations may be affected by the increase the increase in global food prices may increase the awareness of hunger rather than decrease the commitment to subsidies and gifts. Similarly, the relationship between rising food prices and subsidized rights Complicated. However, it is a production-based entity that is biofuels agricultural Very relevant to the protocol. Sen's analysis of food rights is the agriculture of biofuels Important for ethics because the discussion of original food and fuel is the importance of global hunger protocol Shows why the rich dimensions were missed. Based on the income of the urban poor Impact of prices on rights and food rights based on the production of the rural poor Why both the complex role of competing land use in strengthening or weakening It also points out that the answers to that debate must be agreed upon. [41] Crop acreage and yield statistics Various agricultural studies, censuses and statistics Obtained from databases and verified to ensure data quality and consistency Rated. Potential errors in our analyzes create M3 crop databases For variations in the original quality of agricultural figures used and for crop distribution Possible errors in satellite data input and / or statistical linking of these data inputs May be due. . However, most of these errors affect yield and area, They can be reduced when compiling statistics using political boundaries. [42] Organic extraction of agricultural waste (AW) in addition to lingo cellulose components (products by solvent) Leakage) and ash (mineral residue obtained after pyrolysis). Agricultural waste (AW) is a lingo cellulosic biomass consisting of three lingo cellulosic components (10.5-40.4 wt\% hemi Cellulose, $25.0-44.2 \mathrm{wt} \%$ cellulose and $21.7-44.0 \mathrm{wt} \%$ lignin) and extractable incisions. In general, the cellulose content of AW is higher than the content of hemi cellulose and lignin Is. Based on the existing literature, most microwave pyrolysis systems Focus only on non-agricultural feeds, laboratory / package size and product yield Pay, AW, pilot / continuous size and Pays little attention to biofuel energy content. [43].

Straw, nuts, fruit shells, fruit seeds, plant stems and ovens, green leaves and Agricultural residues such as molasses are renewable energy sources. This will remove agricultural waste Current methods have caused widespread environmental concerns. In the economic development of the developing country Agricultural energy or green energy production plays an important role. Its economic growth and agricultural production Based and most people live in rural areas. It is therefore imperative to implement integrated community development programs. It is believed that integrated social development contributes to the socio-economic development of the country. Bio-oils are liquid or gaseous fuels biochemicals by 
biochemical or thermo chemical processes, such as agricultural crops, municipal waste and agricultural and forestry byproducts. [44] The Agrarian Organization is a division of the Ministry of Agriculture with Branches in every province of Iran. Of Agricultural Management and Rural Extension Service Centers Basically each district and each of the rural centers of the province has several subdivisions Have branches. The agronomists working in these areas are in direct contact with the farmers Are engaged in the education and training of farmers. In rural areas and among farmers They are also responsible for implementing government policies. [45] Agricultural Research Centers each in the country Responsible for research in various fields of agriculture in the region. Researchers working in these centers They are not only involved in research but also in training agricultural scientists and farmers. Sugarcane Industries are large plantations that extract sugar throughout the Kuznetsov Oblast. In addition to their general duties, the specialists of such plantations produce sugarcane for the garden Responsible for providing advice to farmers who do. Agriculture in February 2015 The survey was conducted among scientists. Then, completed questionnaires were collected. [46] All agricultural professionals refuse to participate and they are very sensitive They are given the right to consider or refuse to answer any question they may have find embarrassing. These findings revealed that agronomists experience greater sensitivity and greater intensity in the use of conventional fuels. According to common Beliefs, agricultural organizations and research And professionals working in the centers to the community Were more optimistic about the degradation caused by fossil fuels to the environment. than experts in the sugarcane industry. [47] The standard GTAP database covers 57 sectors, including 20 agricultural and processed foods Represent fields. Many biofuels are fodder crops, albeit in relatively large quantities And are combined with non-fodder crops. For example, corn with other coarse grains Is integrated and rapeseed is part of a broader oilseed variety. In this study 2006-2020 How biofuels will affect agricultural producers and consumers over time We create three scenarios to highlight: one reference and two alternatives. Biomass under reference conditions as prices for agricultural products fall (see next section) There is a small increase in fuel production, which is low Ethanol increases the profitability of production despite energy prices. More about this source textSource text required for additional translation information Send feedback Side panels.

\section{Vegetable Oil Bio-Fuels}

Furthermore the micro blast mechanism described by the diffusion-limit model, Unlike the evaporation of pure vegetable oils, during the evaporation of methyl esters of vegetable oil Not noticed. This indicates that there is no steep concentration gradient within the droplet center Involves violent decay of the droplet due to spontaneous internal ventilation. [48] Drops of vegetable oil methyl esters mono- The component evaporates like liquid droplets, but with a very significant temperature. [49] Hydro-treated VGO-vegetable oil blends Hydro-untreated VGO-vegetable That is, they allow for the removal of more sulfur and oxygen compared to oil feed stocks Becomes clear. [50] In terms of oxygen removal, it is better than non-hydro VGO-vegetable oil blends Clearly elevated. Large sulfur in hydrogen untreated VGO at active sites of the catalyst This may be due to the absorption of compounds, thus preventing the catalyst from removing oxygen. Loses part of the process. Also, feed with a small amount of vegetable oil (90/10) Reserves are more likely to be depleted of oxygen, including small amounts of oxygen (containing triglycerides). Is expected to be. It is uniform with feed stocks containing hydro-treated VGO and non-hydro-treated VGO. The results are not straightforward in the case of sulfur removal. [51] Hydro treatment VGO vegetable oil compounds, high VGO content high sulfur removal. At higher temperatures $(390 \mathrm{C})$ the change approaches $70 \%$, significant cracks in both VGO and vegetable oil molecules as lighter materials Indicates. However, when examining the selectivity of diesel, temperature can have a negative effect Becomes clear because it causes cracking of heavier molecules (i.e. above 360 C) Boiling point), but contributes to the lightning of diesel molecules. . The result will be the selection of Naphtha The capacity increases with increasing temperature. [52] Vegetable oil sludge is sourced from the Vietnamese Van Dove Company. Its composition is as follows: Triglycerides (61\%), free fatty acids (37\%) and impurities (2\%). Triglycerides and free The hydrocarbon chains of fatty acids are mainly C16 (30\%) and C18 (36\%) hydrocarbons. Is. Others contained the $\mathrm{C} 12-\mathrm{C} 17$ hydrocarbon chain. Catalyst of integrated material To evaluate the performance, a vegetable oil sludge crack reaction was performed. Of vegetable oil sludge The chromatogram shows that it has a three-part boiling point. Above $343 \mathrm{C}$ All boiling points correspond to sections of HCO. [53] Furthermore, process configuration is highly correlated with nutrient properties; For example, cellulosic High due to high energy fluid and low oxygen content compared to biomass Vegetable oils containing triglyceride can be easily converted into biofuels. In particular,palmitic, oleic and linoleum acids in most vegetable oil feed stocks have unsaturated bases as the primary acids in their structures, as mentioned earlier. Several Types of catalysts for the catalytic cracking process of vegetable oils have been proposed. [54]. This Catalysts are generally classified into four types; Homogeneous catalysts, Multifunction catalysts, biochemicals and nano catalysts with a cross section of less than $100 \mathrm{~nm}$ Are referred to as products of any shape.

Diversity and homogeneous catalysts Often in the catalytic cracks of vegetable oils Are used, and they are classified into different types. [55] Vegetable oil can be catalyzed using homogeneous and multifunctional catalysts, But the reaction rate in a homogeneous catalyst is faster than in multiple layers. Of vegetable oils Although catalytic cracking has been studied in detail, the actual liquid catalyst cracking (FCC) conditions Below is a small discussion of catalytic cracks in vegetable oils. However, some researchers believe the FCC Simulation studies have been carried out on the catalytic cracking of vegetable oils under conditions. Methanol was used in a ratio of 5: $1 \mathrm{M}$ and The catalyst was applied in $1 \% \mathrm{w} / \mathrm{w}$ crude vegetable oil. [56]. No methanol recovery was considered in this study, but no long-term biofuel Production plans should also be considered. Biodiesel conversion efficiency of crude oil is $95 \%$ and SVO is $99 \%$. Estimated as. Purchase of equipment used in the biofuel production process And primary biofuel production capital costs related to financing. Extract the oil Tools, 
processing unrefined vegetable oil into biodiesel or SVO, and storage of biofuels for subsequent use. However, a liter of vegetable oil requires twice as much fodder, and the price increases proportionately. In the long run, the cost of production is usually the market price And will be less volatile than the market price reflects the cost of production more closely than it did in 2007. [57] [58] When upgrading vegetable oils to hydrocarbon biofuels, the inactivation of catalysts is Catalyst is a significant factor in performance and business economics considerations. Catalytic cracking During the process, many side reactions can produce a carbonaceous substance called coke. Coke formation is a major factor in inactivating the catalyst. [59] Exterior of the coke catalyst May be placed on the surface and / or inner holes. First, the correctness of the catalysts used Regeneration will help reduce the cost of biofuel production from vegetable oil upgrades. Second, Vegetable oil due to expensive harvesting / extraction and competition with food resources Fodder is very expensive. In recent years, edible vegetable oil and edible plant Various vegetable oils, including oil, have been studied. [60] However, camellia oil and The use of non-food vegetable oil sources such as waste vegetable oil will be more focused in the future Should be paid, thus reducing costs and reducing competition with food sources. In addition, A reasonable supply of vegetable oil raw materials should be designed to reduce costs.

\section{Conclusion}

Globally, estimates of biofuels are very high. Despite the high price of oil in the world today, tradition Compromise the price of biofuels with dependent fuels Not done. Biofuel Economy 21st Has been growing rapidly for over a century. The growth of the hydrocarbon economy in the last century Designed, the same forces now in the biofuel economy and its biofuel plants Design. Because biofuels have their own merits for the environment, The effective contribution of biofuels to the transportation sector will lead to rapid growth in the future. Biofuels have become an appropriate technology by industrialized and developing countries for a number of reasons Are considered. Three popular ways to grow microalgae for fuel are open pond Systems, closed pool systems and engraved photovoltaics or PBR. Closed The pools are similar to open pools, but they are covered for colder climates. Open pool The system requires stability $15 \mathrm{C}$ temperature, low maintenance, low cost to set up, but yields low. However, the cost of microalgae for biofuel production will become lower and significant barriers have not yet been overcome before the impact on the world's transport fuel supply. Microalgae as a potential source of various food and biological products used in the pharmaceutical industry Is. Practical sources of omega-3 in microalgae are usually ecosapentaenoic acid (EPA). And decosahexaenoic acid (DHA). Ethanol, in contrast to biodiesel, is a composite biofuel Yes, its final composition does not vary depending on the type of feed. Ingredients sugar and starch crops Yes, these are basically by pre-treatment, fermentation and filtration by yeast and other microorganisms Are processed. The main sugar crops are sugarcane and sugar beet. Sweet rice is one of the many uses Ethanol also turns out to be an interesting ingredient, its seeds are edible and the sugar in its stems Is. The main starch crops used today are corn and wheat; More potatoes, Low in cassava and corn grains. Straw, nuts, fruit shells, fruit seeds, plant Renewable agricultural residues such as stalks and stoves, green leaves and molasses Energy sources. Current methods of disposing of these agricultural wastes raise widespread environmental concerns Have caused. Agricultural energy or green energy production plays an important role in the economic development of a developing country Plays. Its economic growth and agricultural production Based and most people live in rural areas. It is therefore imperative to implement integrated community development programs. It is believed that integrated social development contributes to the socio-economic development of the country. Furthermore the micro blast mechanism described by the diffusion-limit model, Unlike the evaporation of pure vegetable oils, during the evaporation of methyl esters of vegetable oil Not noticed. This indicates that there is no steep concentration gradient within the droplet center Involves violent decay of the droplet due to spontaneous internal ventilation.

\section{Reference}

[1]. Gaurav, N., S. Sivasankari, G. S. Kiran, A. Ninawe, and J. Selvin. "Utilization of bioresources for sustainable biofuels: a review." Renewable and Sustainable Energy Reviews 73 (2017): 205-214.

[2]. Brennan, Liam, and Philip Owende. "Biofuels from microalgae - a review of technologies for production, processing, and extractions of biofuels and co-products." Renewable and sustainable energy reviews 14, no. 2 (2010): 557-577.

[3]. Hillman, Karl M., Roald AA Suurs, Marko P. Hekkert, and Björn A. Sandén. "Cumulative causation in biofuels development: a critical comparison of the Netherlands and Sweden." Technology Analysis \& Strategic Management 20, no. 5 (2008): 593-612.

[4]. Xu, Lixian, Derk WF Wim Brilman, Jan AM Withag, Gerrit Brem, and Sascha Kersten. "Assessment of a dry and a wet route for the production of biofuels from microalgae: energy balance analysis." Bioresource technology 102, no. 8 (2011): 5113-5122.

[5]. Thompson, Paul B. "The agricultural ethics of biofuels: a first look." Journal of agricultural and environmental ethics 21, no. 2 (2008): 183-198.

[6]. Nerkar, T., and V. Karnad. "ECO-FRIENDLY CLOTHING-Comparison of organic cotton, bamboo and linen towards product development for infant wear." Colourage 58, no. 7 (2011): 54. 
[7]. Mulchandani, Neha, and Vishaka Karnad. "Application of Zinc Oxide nanoparticles on Cotton fabric for imparting Antimicrobial properties." International Journal for Environmental Rehabilitation and Conservation 11, no. 1 (2020): 1-10.

[8]. Mulchandania, Neha, and Vishaka Karnad. "Understanding users perspective for surgical apparel." Man-Made Textiles in India 46, no. 4 (2018).

[9]. Jain, Ms Namrata, and Vishaka Karnad. "Online Forms for Data Collection and its Viability in Fashion and Consumer Buying Behavior Survey-A Case Study." (2017).

[10]. Sompura, P., and V. Karnad. "POLYESTER-Product development from spun silk/polyester fabrics printed with geometric motifs and newsprints for home interiors." Colourage 58, no. 3 (2011): 40.

[11]. Mulchandani, Neha, and Vishaka Karnad. "Application of zinc oxide nano particles using polymeric binders on cotton fabric." Research Journal of Textile and Apparel (2021).

[12]. Dedhia, E. M., and V. S. Amembal. "A comparative study of magnesium chloride and sodium chloride as electrolytes for direct dyeing." Colourage 45, no. 8 (1998): 35-37.

[13]. Gao, Xue, Jin-Chun Chen, Qiong Wu, and Guo-Qiang Chen. "Polyhydroxyalkanoates as a source of chemicals, polymers, and biofuels." Current opinion in biotechnology 22, no. 6 (2011): 768-774.

[14]. Dugar, Deepak, and Gregory Stephanopoulos. "Relative potential of biosynthetic pathways for biofuels and biobased products." Nature biotechnology 29, no. 12 (2011): 1074-1078.

[15]. Chang, Ting-Huan, and Hsin-Mei Su. "The substitutive effect of biofuels on fossil fuels in the lower and higher crude oil price periods." Energy 35, no. 7 (2010): 2807-2813.

[16]. Singh, Jasvinder, and Sai Gu. "Commercialization potential of microalgae for biofuels production." Renewable and sustainable energy reviews 14, no. 9 (2010): 2596-2610.

[17]. Patil, Vishwanath, Khanh-Quang Tran, and Hans Ragnar Giselrød. "Towards sustainable production of biofuels from microalgae." International journal of molecular sciences 9, no. 7 (2008): 1188-1195.

[18]. Leite, Gustavo B., Ahmed EM Abdelaziz, and Patrick C. Hallenbeck. "Algal biofuels: challenges and opportunities." Bioresource technology 145 (2013): 134-141.

[19]. Fegade, Vishal, R. L. Shrivatsava, and A. V. Kale. "Design for remanufacturing: methods and their approaches." Materials Today: Proceedings 2, no. 4-5 (2015): 1849-1858.

[20]. Ramachandran, M., Sahas Bansal, Vishal Fegade, and Pramod Raichurkar. "Analysis of bamboo fibre composite with polyester and epoxy resin." International Journal on Textile Engineering \& Processes 1, no. 4 (2015): 18-21.

[21]. Fegade, Vishal, Gajanan Jadhav, and M. Ramachandran. "Design, Modelling and Analysis of Tilted Human Powered Vehicle." In IOP Conference Series: Materials Science and Engineering, vol. 377, no. 1, p. 012215. IOP Publishing, 2018.

[22]. Bhanushali, R., and V. Karnad. "Dyeing of cotton and silk using vegetable kitchen waste: a step towards sustainability." S. No. Title of Paper Page No.: 28.

[23]. Ramachandran, M., Vishal Fegade, and P. P. Raichurkar. "Strategy Performance Evaluation of a Port Organisation based on Multi-Criteria Decision Making using Fuzzy Logic Method." NMIMS Management Review 33 (2017): $27-$ 34.

[24]. Ragavendran, U., Viral Mehta, Vishal Fegade, and M. Ramachandran. "Dynamic Analysis of Single Fold Symmetric Composite Laminates." international Journal of civil Engineering and Technology 8, no. 11 (2017): 536545.

[25]. Fegade, V. T., and Kiran S. Bhole. "Finite Element Analysis and Material Optimization for Equivalent Strength of Composite Connecting Rod." SSRG International Journal of Mechanical Engineering (SSRG-IJME) 2, no. 2 (2015).

[26]. Singh, Anoop, Poonam Singh Nigam, and Jerry D. Murphy. "Mechanism and challenges in commercialisation of algal biofuels." Bioresource technology 102, no. 1 (2011): 26-34.

[27]. Shuba, Eyasu Shumbulo, and Demeke Kifle. "Microalgae to biofuels:'Promising'alternative and renewable energy, review." Renewable and Sustainable Energy Reviews 81 (2018): 743-755.

[28]. Khan, Muhammad Imran, Jin Hyuk Shin, and Jong Deog Kim. "The promising future of microalgae: current status, challenges, and optimization of a sustainable and renewable industry for biofuels, feed, and other products." Microbial cell factories 17, no. 1 (2018): 1-21.

[29]. Parmar, Asha, Niraj Kumar Singh, Ashok Pandey, Edgard Gnansounou, and Datta Madamwar. "Cyanobacteria and microalgae: a positive prospect for biofuels." Bioresource technology 102, no. 22 (2011): 10163-10172.

[30]. Milledge, John J. "Commercial application of microalgae other than as biofuels: a brief review." Reviews in Environmental Science and Bio/Technology 10, no. 1 (2011): 31-41. 
[31]. Schenk, Peer M., Skye R. Thomas-Hall, Evan Stephens, Ute C. Marx, Jan H. Mussgnug, Clemens Posten, Olaf Kruse, and Ben Hankamer. "Second generation biofuels: high-efficiency microalgae for biodiesel production." Bioenergy research 1, no. 1 (2008): 20-43.

[32]. Koh, Lian Pin, and Jaboury Ghazoul. "Biofuels, biodiversity, and people: understanding the conflicts and finding opportunities." Biological conservation 141, no. 10 (2008): 2450-2460.

[33]. Nigam, Poonam Singh, and Anoop Singh. "Production of liquid biofuels from renewable resources." Progress in energy and combustion science 37, no. 1 (2011): 52-68.

[34]. Demirbas, Muhammed Fatih, and Mustafa Balat. "Recent advances on the production and utilization trends of biofuels: a global perspective." Energy Conversion and Management 47, no. 15-16 (2006): 2371-2381.

[35]. Shanmugasundar, G., B. Karthikeyan, P. Santhosh Ponvell, and V. Vignesh. "Optimization of process parameters in TIG welded joints of AISI 304L-austenitic stainless steel using Taguchi's experimental design method." Materials Today: Proceedings 16 (2019): 1188-1195.

[36]. Shanmugasundar, G., R. Sivaramakrishnan, S. Meganathan, and S. Balasubramani. "Structural optimization of an five degrees of freedom (T-3R-T) robot manipultor using finite element analysis." Materials Today: Proceedings 16 (2019): 1325-1332.

[37]. Shanmugasundar, G., and R. Sivaramakrishnan. "A Survey on Development of Inspection Robots: Kinematics Analysis, Workspace Simulation and Software Development." International Review Of Mechanical Engineering 6, no. 7 (2012): 1493-1507.

[38]. Gadde Mehar Chaitanya, M.P.Jenarthanan, C. Sathiyaraj, "A Review on Glass fibre Reinforced Composites with Different Matrix", REST Journal on Emerging trends in Modelling and Manufacturing, 7(1), (2021):18-24.

[39]. Sai Krishnan, G., Raghuram Pradhan, and Ganesh Babu Loganathan. "Investigation on Mechanical Properties of Chemically Treated Banana and Areca Fiber Reinforced Polypropylene Composites." In Advances in Lightweight Materials and Structures, pp. 273-280. Springer, Singapore, 2020.

[40]. Sundar, G. Shanmuga, R. Sivaramakrishnan, and S. Venugopal. "Design and developments of inspection robots in nuclear environment: A review." Int. J. Mech. Eng. Rob. Res 1 (2012): 400-409.

[41]. Krishnan, G. Sai, J. Pravin Kumar, G. Shanmugasundar, M. Vanitha, and N. Sivashanmugam. "Investigation on the alkali treatment of Demostachya Bipinnata fibers for automobile applications-A green composite." Materials Today: Proceedings 43 (2021): 828-831.

[42]. Fischer, Curt R., Daniel Klein-Marcuschamer, and Gregory Stephanopoulos. "Selection and optimization of microbial hosts for biofuels production." Metabolic engineering 10, no. 6 (2008): 295-304.

[43]. Puricelli, Stefano, Giuseppe Cardellini, S. Casadei, D. Faedo, A. E. M. Van den Oever, and M. Grosso. "A review on biofuels for light-duty vehicles in Europe." Renewable and Sustainable Energy Reviews 137 (2021): 110398.

[44]. Bessou, Cécile, Fabien Ferchaud, Benoît Gabrielle, and Bruno Mary. "Biofuels, greenhouse gases and climate change." Sustainable Agriculture Volume 2 (2011): 365-468.

[45]. Johnston, Matt, Jonathan A. Foley, Tracey Holloway, Chris Kucharik, and Chad Monfreda. "Resetting global expectations from agricultural biofuels." Environmental Research Letters 4, no. 1 (2009): 014004.

[46]. Ge, Shengbo, Peter Nai Yuh Yek, Yoke Wang Cheng, Changlei Xia, Wan Adibah Wan Mahari, Rock Keey Liew, Wanxi Peng et al. "Progress in microwave pyrolysis conversion of agricultural waste to value-added biofuels: A batch to continuous approach." Renewable and Sustainable Energy Reviews 135 (2021): 110148.

[47]. Bakhtiyari, Ziba, Masoud Yazdanpanah, Masoumeh Forouzani, and Navab Kazemi. "Intention of agricultural professionals toward biofuels in Iran: Implications for energy security, society, and policy." Renewable and Sustainable Energy Reviews 69 (2017): 341-349.

[48]. Soniya Sriram, M. Ramachandran, Sathiyaraj Chinnasamy, G. Mathivanan "A Review on Multi-Criteria DecisionMaking and Its Application", REST Journal on Emerging trends in Modelling and Manufacturing, 7(4), (2022):101107.

[49]. Lokhande, Dr Amol, Dr C. Venkateswaran, Dr M. Ramachandran, S. Chinnasami, and T. Vennila. "A Review on Various Implications on Re engineering in Manufacturing." REST Journal on Emerging trends in Modelling and Manufacturing 7, no. 3 (2021): 70-75.

[50]. Huang, Jikun, Jun Yang, Siwa Msangi, Scott Rozelle, and Alfons Weersink. "Biofuels and the poor: Global impact pathways of biofuels on agricultural markets." Food policy 37, no. 4 (2012): 439-451.

[51]. Morin, Celine, Christian Chauveau, and Iskender Gökalp. "Droplet vaporisation characteristics of vegetable oil derived biofuels at high temperatures." Experimental Thermal and Fluid Science 21, no. 1-3 (2000): 41-50.

[52]. Bezergianni, Stella, Aggeliki Kalogianni, and Iacovos A. Vasalos. "Hydrocracking of vacuum gas oil-vegetable oil mixtures for biofuels production." Bioresource Technology 100, no. 12 (2009): 3036-3042. 
[53]. Vinh, Tran Quang, Nguyen Thi Thanh Loan, Xiao-Yu Yang, and Bao-Lian Su. "Preparation of bio-fuels by catalytic cracking reaction of vegetable oil sludge." Fuel 90, no. 3 (2011): 1069-1075.

[54]. Vimala Saravanan; M. Ramachandran; T. Vennila; G. Mathivanan "A Study on Multi-Objective Optimization on the basis of Ratio Analysis", Recent trends in Management and Commerce, 2(3), (2021):16-22

[55]. Naji, Samah Zaki, Ching Thian Tye, and Ammar Ali Abd. "State of the art of vegetable oil transformation into biofuels using catalytic cracking technology: Recent trends and future perspectives." Process Biochemistry 109 (2021): 148-168.

[56]. Fore, Seth R., William Lazarus, Paul Porter, and Nicholas Jordan. "Economics of small-scale on-farm use of canola and soybean for biodiesel and straight vegetable oil biofuels." biomass and bioenergy 35, no. 1 (2011): 193202.

[57]. Gaurav, N., S. Sivasankari, G. S. Kiran, A. Ninawe, and J. Selvin. "Utilization of bioresources for sustainable biofuels: a review." Renewable and Sustainable Energy Reviews 73 (2017): 205-214.

[58]. Zhao, Xianhui, Lin Wei, Shouyun Cheng, and James Julson. "Review of heterogeneous catalysts for catalytically upgrading vegetable oils into hydrocarbon biofuels." Catalysts 7, no. 3 (2017): 83.

[59]. Nisha Sherief; M. Anand; M. Ramachandran; Vidhya Prasanth, "A Review on Various Biofuels and its Applications", REST Journal on Emerging trends in Modelling and Manufacturing, 8(1), (2022):1-9.

[60]. R. Kurinjimalar, S. Vimala, M. Silambarasan, S. Chinnasami. "A Review on Coir fibre Reinforced Composites with Different Matrix", REST Journal on Emerging trends in Modelling and Manufacturing, 7(2), (2021):25-32. 